\title{
Recent Trends and Challenges with COVID-19 - Africa, April 4, 2020
}

\author{
Xiaochun Wang1, ${ }^{1,2 *} ;$ Shuo Chen ${ }^{1}$; Feng Tan'; George F. Gao
}

\section{Summary}

What is already known about this topic?

Since the first COVID-19 confirmed case was reported, the current epidemic in Africa has rapidly increased.

What is added by this report?

As of April 4, 2020, a total of 7,405 confirmed cases and 305 deaths had been reported from 51 countries across Africa. The cumulative number of reported COVID-19 cases varied among the five regions of Africa, of which northern Africa reported the largest number of confirmed cases. The five countries with the highest number of cases are South Africa, Algeria, Egypt, Morocco, and Tunisia.

What are the implications for public health practice?

Early detection, early isolation, early reporting, and early treatment of the COVID-19 are important and critical measures for the successful control of further transmission of COVID-19. Now more stringent prevention and control measures have been implemented in Africa, but due to often insufficient basic medical facilities and medical services, Africa is still facing challenges to the pandemic and needs to strengthen national health systems and develop immediate and future health plans.

The first confirmed case of coronavirus disease 2019 (COVID-19) in Africa was reported in Egypt on February 15, 2020 (1). As of April 4, 2020, 50 days after the first confirmed case was reported, a total of 7,405 confirmed cases and 305 deaths had been reported from 51 countries across Africa (2). In the 50 days since the first case was reported in Africa, COVID-19 spread relatively slow, especially in the first 20 days with 22 confirmed cases reported in 6 countries. However, by Day 23, the number of confirmed cases reported started increasing every day. By Day 30, 24 countries had reported a total of 251 confirmed cases; by Day 40, a total of 2,245 confirmed cases had been reported in 44 countries; by Day 50, the cumulative number of confirmed cases reported in
51 countries had grown rapidly to 7,405 (3) (Figure 1).

The cumulative number of reported COVID-19 cases varied among the 5 regions of Africa with the number of cases growing most rapidly in Northern Africa, which, as of April 4, 2020, reported 3,382 confirmed cases and accounted for $45.31 \%$ of the total reported cases in Africa. The number of cases reported in Central Africa and Eastern Africa increased more slowly, with 473 and 669 reported cases and $6.34 \%$ and $8.96 \%$ of the total reported cases in Africa, respectively (2). The 5 countries with the highest total numbers of confirmed cases are South Africa $(1,505$ cases), Algeria (986 cases), Egypt (985 cases), Morocco (844 cases), and Tunisia (495 cases), and they cumulatively reported a total of 4,815 confirmed cases, which accounts for $65.02 \%$ of the total reported cases in Africa. (2)

With an increase in the number of reported cases of the COVID-19 in Africa, there is extreme concern for whether Africa will reach a level of emergency that Europe reached, which as of April 4, 2020, the cumulative number of reported cases of the COVID19 in Europe has reached 541,171 (2). The first confirmed case in Europe was reported by France on January 25, 2020 (4), and by Day 36 after the first case was reported, more than 1,000 cases were reported (5) and more than 5,000 cases were reported by Day 42 in Europe (6). Comparing the epidemic development in Europe, Africa reported more than 1,000 cases on Day 37 after the first case was reported $(7)$ and more than 5,000 cases by Day 46 (8).

From the first case report to Day 35, the number of reported cases and the growth rate were almost identical in Europe and Africa. However, after Day 35, the growth of the number of reported cases in Europe began to accelerate when compared with Africa, and by Day 50, Europe reported 36,264 cases while Africa reported 7,405 cases. By Day 60 (9), the cumulative number of the reported cases in Europe had reached nearly 200,000 (195,262 cases) and by Day 70, it had reached well over 500,000 (541,171 cases) (10) (Figure 2). Epidemic trends in Europe remind us that the next three to four weeks will be a crucial time for 
the development of the COVID-19 epidemic in Africa. Will Africa experience a sudden and rapid increase in the number of reported cases as Europe did?
The World Health Organization (WHO) classified the transmission modes of the COVID-19 as imported cases only, local transmission, and community
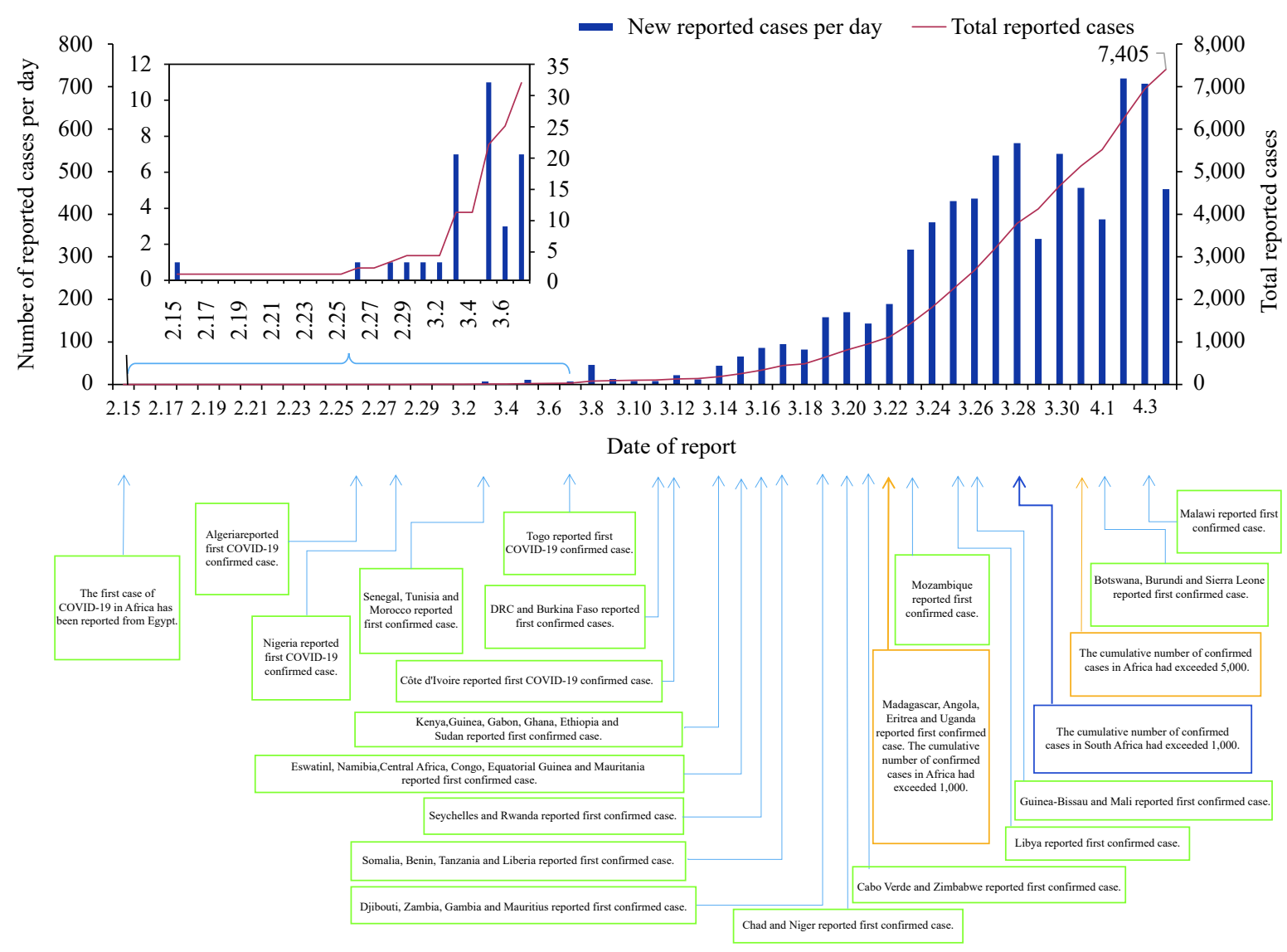

FIGURE 1. COVID-19 cases reported by day in Africa.

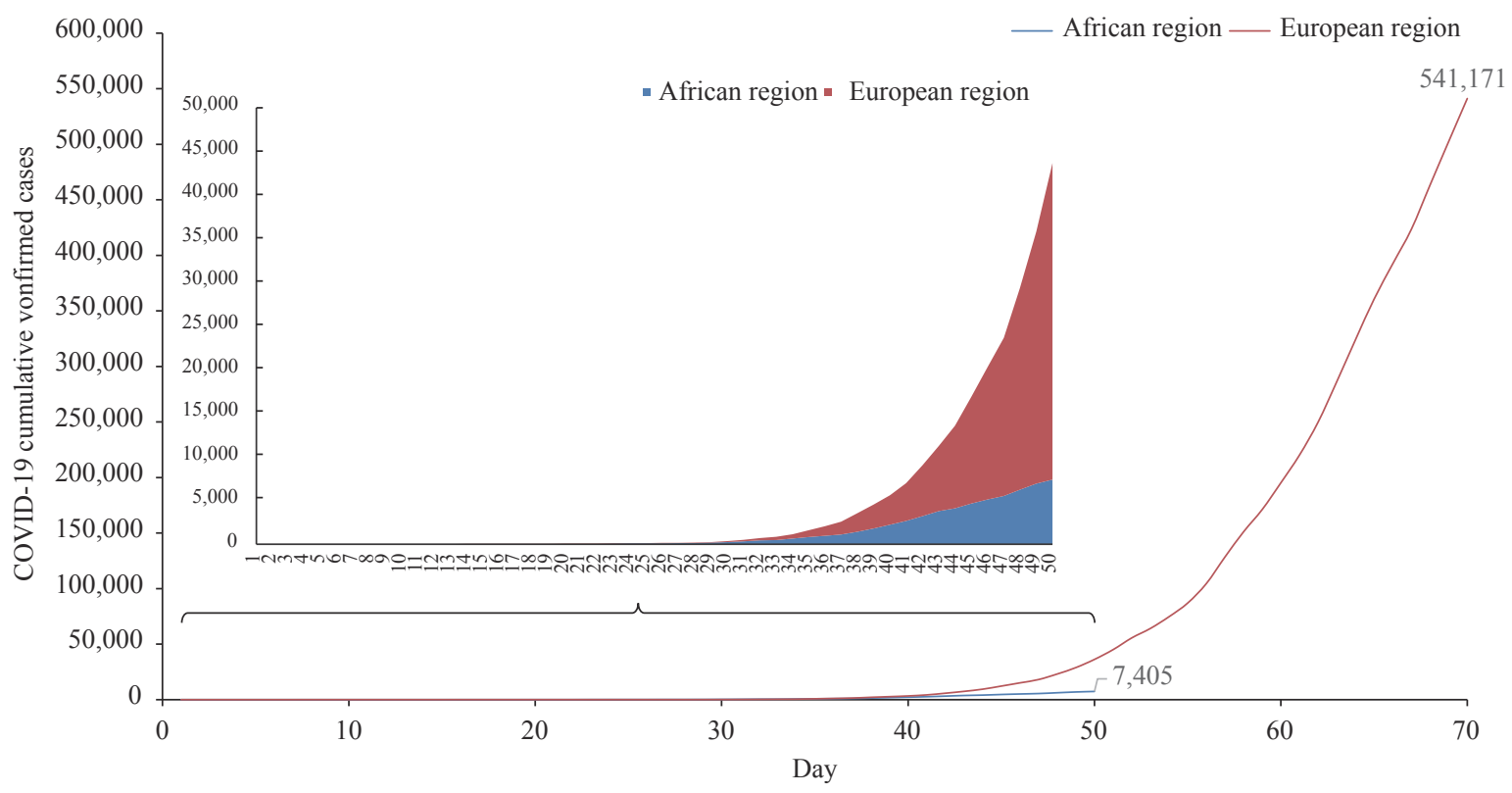

FIGURE 2. COVID-19 cases reported by day after the first case was reported in Africa and Europe. 
transmission. The imported cases only classification indicates locations where all cases have infections acquired from outside of the reporting location. Local transmission indicates locations where the source of infection is within the reporting location (2). The changes in transmission modes of COVID-19 in 54 countries in Africa and 53 countries in Europe are almost identical. As the number of countries reporting COVID-19 cases increases, so does the number of countries that are changing from imported cases only to local transmission. As of April 4, 2020, 66.67\% (36/54) of countries in Africa were classified as having local transmission and 25.93\% (14/54) were imported cases only $(2,11)$ (Figure 3A); but by this time, $96.23 \%$ (51/53) of countries in Europe were classified as having local transmission and only $3.77 \%$ (2/53) were imported cases only (2). In Europe, 60 days after the first case was reported, more than $90 \%$ of countries with COVID-19 were classified as having local transmission, and the cumulative number of reported cases also increased rapidly to nearly 200,000 $(195,262$ cases) (9-10) (Figure 3B).

\section{DISCUSSION}

The number of confirmed COVID-19 cases detected and reported in each country are influenced by many factors including effective interventions, expanding test strategies, and strict infectious source management. With regard to the number of confirmed cases currently reported, there may be a problem in Africa that the number of reported confirmed cases may be lower than the actual number of infections due to restraints in testing capacity and number of tests available in African countries.

"The Four Early Measures" (Early Detection, Early Isolation, Early Reporting, and Early Treatment) of COVID-19 are important and critical to the successful control of further transmission of the coronavirus (12-13). Expanded testing is a much-needed strategy that countries in Africa urgently need to strengthen, especially for the screening of key populations (14). The development of the COVID-19 epidemic from Europe suggests that the epidemic in Africa will become more severe if comprehensive control measures are not firmly implemented as increasing numbers of African countries transition into having local transmission and community transmission.

From the response strategy to COVID-19 adopted by most African countries, more strict prevention and control measures for COVID-19 have been implemented in Africa. To prevent imported

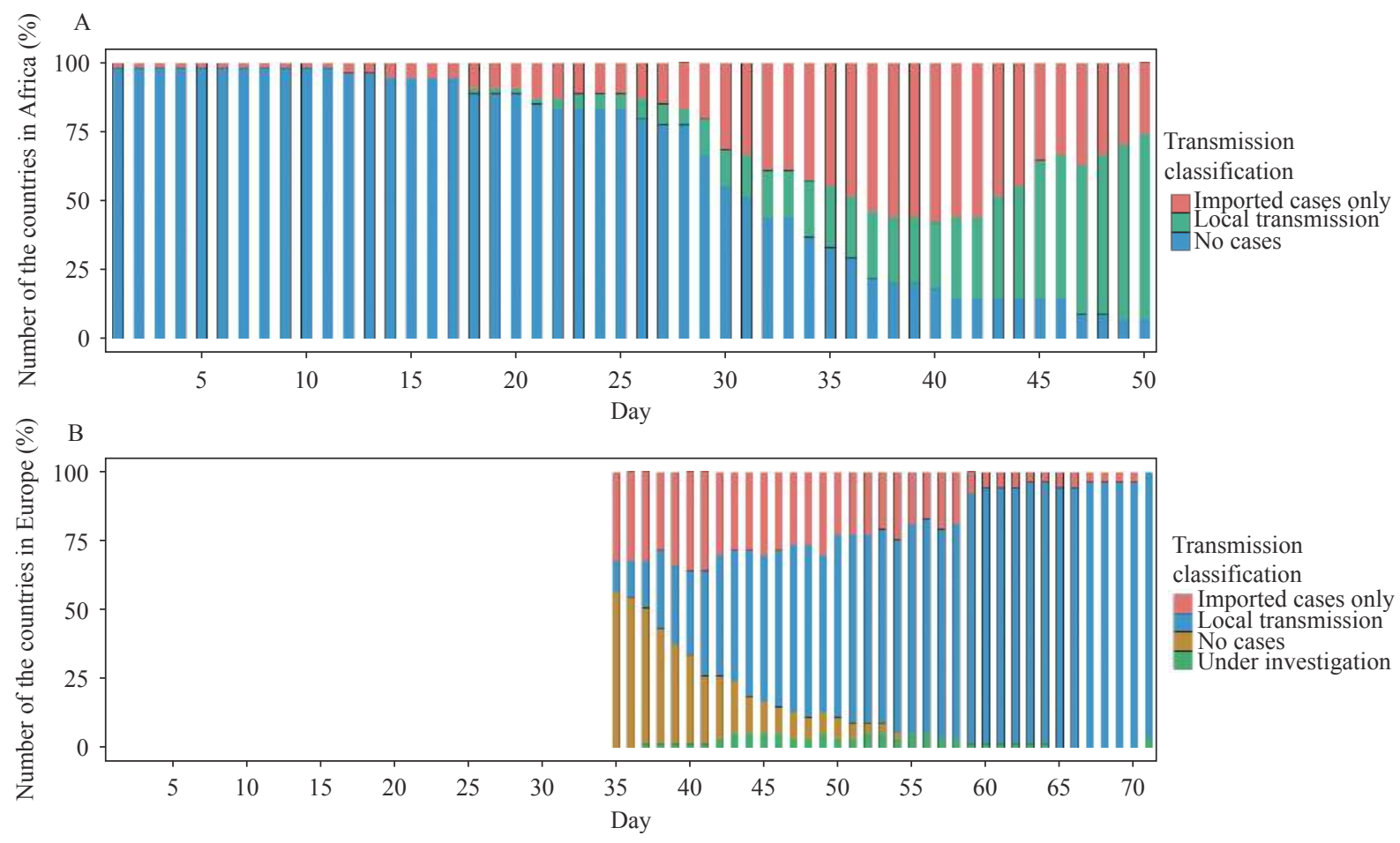

FIGURE 3. Changes in transmission modes of COVID-19 in African (A) and European (B) countries after the first case was reported. In the first 35 days after the first case report, there was no data on COVID-19 transmission in European countries. 
transmission of COVID-19, most African countries have closed their borders, and a few have closed international air traffic or imposed travel restrictions to and from specific countries. Virtually almost all African countries have imposed mandatory quarantine measures for all travelers or travelers arriving from high-risk areas of COVID-19. In order to control local transmission and community transmission of the COVID-19, most African countries have implemented special measures for social distancing and movement restriction including closure of educational institutions, banning public gatherings, and closing public spaces. Some African countries are imposing national and partial lockdown or curfews at night with the aim of severely restricting non-essential movement. These measures may be directly responsible for the slowed growth of the COVID-19 epidemic in Africa since the first confirmed case was reported (15).

On April 4, 2020, 50 days after the first case was reported in Africa, the cumulative number of confirmed cases worldwide exceeded 1 million $(1,051,697)$ with nearly 57,000 deaths. On that day, 79,394 new confirmed cases and 6,665 deaths were reported globally, with the majority of the new confirmed cases and deaths concentrated in the United States and Europe (2). Africa, the world's second largest continent, is facing challenges in the face of the global COVID-19 pandemic. First, the number of confirmed cases and the number of affected countries are increasing rapidly; second, the number of countries switching from imported transmission to local and community transmission is increasing rapidly; third, although many necessary prevention and control measures have been taken, many African countries are not yet ready for specific measures on how to respond to the impending community transmission of COVID-19; fourth, the capacity of basic medical facilities and medical services in many African countries are insufficient, making it difficult to respond to a sudden increase in COVID-19 cases.

The COVID-19 adds an additional disease burden to already existing priority diseases in Africa, such as AIDS, tuberculosis, malaria, and viral hepatitis, and emerging and re-emerging infectious diseases, such as Ebola, dengue, yellow fever, Lassa fever, cholera, and measles, which are still affecting African countries $(16-17)$. Frequent outbreaks of these infectious diseases have repeatedly struck and undermined Africa's already strained public health systems. The COVID-19 pandemic has again sounded the alarm in Africa, which urgently needs to strengthen national health systems and develop and implement plans for health development. Only by truly improving the capacity of infectious disease prevention and control and the comprehensive capacity of public health can Africa ensure economic and social development and global health security (18).

doi: $10.46234 /$ ccdcw 2020.094

\# Corresponding author: Xiaochun Wang, wangx@africa-union.org. ${ }^{1}$ Chinese Center for Disease Control and Prevention, Beijing, China;
${ }^{2}$ Africa Centers for Disease Control and Prevention, Addis Ababa,
Ethiopia.

Submitted: April 26, 2020; Accepted: April 27, 2020

\section{REFERENCES}

1. World Health Organization. Coronavirus disease 2019 (COVID-19) situation report - 26. https:/www.who.int/docs/default-source/coron aviruse/situation-reports/20200215-sitrep-26-covid-19.pdf. [2020-0427].

2. World Health Organization. Coronavirus disease 2019 (COVID-19) situation report - 75. https:/www.who.int/docs/default-source/coron aviruse/situation-reports/20200404-sitrep-75-covid-19.pdf. [2020-0426].

3. World Health Organization. Coronavirus disease 2019 (COVID-19) situation report. https:/www.who.int/emergencies/diseases/novel-coron avirus-2019/situation-reports. [2020-04-26].

4. World Health Organization. Novel coronavirus (2019-nCoV) situation report, 5. https://apps.who.int/iris/handle/10665/330769. [2020-04-26].

5. World Health Organization. Coronavirus disease 2019 (COVID-19) situation report, 40. https:/www.who.int/docs/default-source/corona viruse/situation-reports/20200229-sitrep-40-covid-19.pdf. [2020-0426].

6. World Health Organization. Coronavirus disease 2019 (COVID-19) situation report - 46. https:/www.who.int/docs/default-source/coron aviruse/situation-reports/20200306-sitrep-46-covid-19.pdf. [2020-0426].

7. World Health Organization. Coronavirus disease 2019 (COVID-19) situation report - 62. https:/www.who.int/docs/default-source/coron aviruse/situation-reports/20200322-sitrep-62-covid-19.pdf.[2020-0426].

8. World Health Organization. Coronavirus disease 2019 (COVID-19) situation report - 71. https:/www.who.int/docs/default-source/coron aviruse/situation-reports/20200331-sitrep-71-covid-19.pdf.[2020-0426].

9. World Health Organization. Coronavirus disease 2019 (COVID-19) situation report - 64. https:/www.who.int/docs/default-source/coron aviruse/situation-reports/20200324-sitrep-64-covid-19.pdf.[2020-0426].

10. World Health Organization. Coronavirus disease 2019 (COVID-19) situation report - 74. https:/www.who.int/docs/default-source/coron aviruse/situation-reports/20200403-sitrep-74-covid-19-mp.pdf.[202004-26].

11. Africa CDC. Outbreak brief number 12: COVID-19 Pandemic - 7 April 2020. https://africacdc.org/download/outbreak-brief-12-covid-19pandemic-7-april-2020/.[2020-04-26].

12. Special Expert Group for Control of the Epidemic of Novel Coronavirus Pneumonia of the Chinese Preventive Medicine Association, The Chinese Preventive Medicine Association. An update on the epidemiological characteristics of Novel Coronavirus Pneumonia (COVID-19). Chin J Epidemiol 2020;41(2):139 - 44. http://dx.doi.org/ 10.3760/cma.j.issn.0254-6450.2020.02.002. (In Chinese).

13. World Health Organization. Report of the WHO-China joint mission 
on coronavirus disease 2019 (COVID-19). https://www.who.int/ docs/default-source/coronaviruse/who-china-joint-mission-on-covid19---final-report-1 100hr-28feb2020-11 mar-update.pdf?sfvrsn=1a13fd a0_2\&downloa=true.[2020-03-01].

14. Fisher D, Smith AW. The global community needs to swiftly ramp up the response to contain COVID-19. Lancet. 2020; 395(10230): 1109 10. https://doi.org/10.1016/S0140-6736(20)30679-6.

15. Nkengasong JN, Wessam M. Looming threat of COVID-19 infection in Africa: act collectively, and fast. Lancet 2020;395(10227):841 - 2 . http://dx.doi.org/10.1016/S0140-6736(20)30464-5.
16. World Health Organization Regional Office for Africa. Weekly bulletin on outbreaks and other emergencies. https://www.afro.who.int/healthtopics/disease-outbreaks/outbreaks-and-other-emergencies-updates. [2020-04-27].

17. Gao GF. From "A"IV to "Z"IKV: attacks from emerging and reemerging pathogens. Cell 2018;172(6):1157 - 9. http://dx.doi.org/10. 1016/j.cell.2018.02.025.

18. Gao GF, John NN. Public health priorities for China-Africa cooperation. Lancet public-health 2019;4(4):e177 - 8. http://dx.doi.org/ $10.1016 /$ S2468-2667(19)30037-4. 